DOI 10.37882/2223-2966.2020.10.13

\title{
ЭКОНОМИЧЕСКАЯ ОЦЕНКА БИОЛОГИЧЕСКИХ РЕСУРСОВ: ПЕРСПЕКТИВЫ И РОЛЬ В СОХРАНЕНИИ БИОРАЗНООБРАЗИЯ
}

\section{ECONOMIC ASSESSMENT OF BIOLOGICAL RESOURCES: PROSPECTS AND IMPORTANCE IN CONSERVATION OF BIODIVERSITY}

\section{Yu. Kirillova}

Summary: Reducing the planet's biodiversity is an acute and global problem facing humanity, which requires modern approaches to its solution. One of these approaches, which is still in the development stage in Russia, but is quite relevant in foreign countries, is the economic assessment of ecosystem services. In order to clarify the prospects of this method in nature conservation, and in particular, the protection of rare and endangered species, an analysis of the socio-economic relations arising from the adoption of the organization of nature management and the interaction of society with the natural environment has been carried out. As a result of the study, it is shown that at this stage of the development of society, within the framework of solving environmental problems, the introduction of an economic mechanism into wide practice is a necessary condition for the preservation of biological diversity and natural resources. The application of a universal economic assessment of ecosystem services and biological resources of various biogeocenoses, and especially in protected areas, will be an important step in ensuring rational nature management and effective planning of environmental protection activities.

Keywords: economic assessment of biological resources, ecosystem services, protection of rare species, conservation of biodiversity, red books, nature conservation.

\author{
Кириллова Юлия Александровна \\ аспирант, Санкт-Петербургский государственный \\ университет \\ yulya_kirillova6@mail.ru
}

Аннотация: Сокращение биоразнообразия планеты - острая и глобальная проблема, стоящая перед человечеством, которая требует современных подходов в ее решении. Одним из таких подходов, находящихся в России еще в стадии развития, но достаточно актуальных в зарубежных странах, является экономическая оценка экосистемных услуг. С целью выяснения перспективности данного метода в природоохранной деятельности, и в частности, охране редких и находящихся под грозой исчезновения видов, проведен анализ социально-экономических отношений, возникающих при принятии организации природопользования и взаимодействии общества с окружающей природной средой. В результате исследования показано, что на данном этапе развития общества в рамках решения экологических проблем внедрение в широкую практику именно экономического механизма является необходимым условием сохранения биологического разнообразия и природных ресурсов. Применение универсальной экономической оценки экосистемных услуг и биологических ресурсов различных биогеоценозов, и особенно на 00ПТ, станет важным шагом обеспечения рационального природопользования и эффективного планирования природоохранной деятельности.

Ключевые слова: экономическая оценка биологических ресурсов, экосистемные услуги, охрана редких видов, сохранение биоразнообразия, красные книги, природоохранная деятельность. окращение биологического разнообразия планеты является одной из самой злободневной проблем нашего времени. Темпы ее обострения и серьезность последствий настолько велики, что необходимость принятия срочных мер и современных подходов в ее решении неоспоримы. Тем не менее, как показывает современная действительность, интересы природы зачастую уступают первенство экономической и политической выгоде. В связи с тем, что финансовая составляющая является основополагающей при принятии решений, появляется необходимость внедрения экономической оценки природных компонентов и экосистем.

В рамках исследования UNEP предложена и широко используется в настоящее время следующая классификация базовых экосистемных услуг:

1. Обеспечивающие услуги, непосредственно эксплуатируемые человеком (продовольствие, вода, материалы). Оценка данного типа услуг относи- тельно проста и производится на основе данных об объемах ресурса и стоимости его на рынке.

2. Регулирующие услуги, представляющие собой самовосстанавливающие механизмы и естественное регулирование климата, состава воздуха, водных ресурсов и эрозийных процессов, стихийных бедствий и заболеваемости живых организмов, способствующие круговороту веществ; также включающие опыление и преобразование отходов. Оценка услуг данной категории производится исходя из затрат, потребующихся на очистку воздуха, воды, здравоохранительные мероприятия, восстановление природных объектов при нарушении экосистем или прекращении выполнения ими саморегуляции.

3. Поддерживающие услуги, обеспечивающие функционирование остальных услуг (почвообразовательные процессы, фотосинтез, круговорот веществ, поставление первичной продукции). 
Метод оценки аналогичен применяемому методу при оценке регулирующих услуг.

4. Культурные услуги включают информационную, гедоническую, эстетическую, духовную, эмоциональную и религиозную ценности, которые общество получает от взаимодействия с природной средой. При оценке учитывается сумма, которую готовы заплатить туристы и посетители природных комплексов за использование территории в рекреационных и прочих целях [1].

В России экономический подход к определению ценности экосистем в представлении экосистемных услуг находится в самом начале своего развития и не имеет должного прикладного значения: денежные оценки биологических ресурсов биогеоценозов являются точечными и носят в основном региональный характер.

Предварительные усредненные удельные денежные оценки экосистемных услуг природных ландшафтов России, приведенные в Пятом национальном докладе «Сохранение биоразнообразия в Российской Федерации» при участии Министерства природных ресурсов и экологии Российской Федерации и Всемирного фонда дикой природы, подготовленном во исполнение решения X/10 10 Конференции Сторон Конвенции о биологическом разнообразии, при их адаптации к региональным биогеосистемным особенностям могут послужить базой при проведении стоимостной оценки экосистем. В рамках указанной работы проведен анализ 10 видов экосистемных услуг с подбором подходящего метода оценки и выражением удельной величины стоимости каждой из них (руб. на 1 га в год) [2].

Приведенная оценка экосистемных услуг природных ландшафтов России отличается от стоимости экосистемных услуг для различных типов биомов, рассчитанной Р. Констанза [3] на основе удельных показателей для США, которая до настоящего времени не потеряла актуальность и используется при проведении расчетов. Данная оценка является наиболее комплексной, в рамках нее рассчитаны общая и глобальная стоимости 17 видов экосистемных услуг с учетом их наличия в каждом типе биомов планеты [4].

На законодательном уровне принят экономический механизм подсчета ущерба, причиненного объектам растительного и животного мира, занесенным в Красную книгу РФ, а также среде их обитания [5, 6, 7]. Однако аналогичная методика определения вреда видам, охраняемым на региональном уровне, не разработана.

Стоит отметить, что виды, не занесенные в красные книги и не используемые в хозяйственной деятельности человека, зачастую играют далеко не последнюю роль в биологических и энергетических циклах биоценозов, занимая определенную экологическую нишу и конкретное место в трофических сетях экосистемы. Поэтому в рамках экономической оценки биоразнообразия применение такс для исчисления вреда видам, занесенным в Красную книгу РФ, в отношении остальных представителей флоры и фауны вполне целесообразно с учетом моделирования исчезновения их с территории оцениваемого участка биогеоценоза.

Внедрение в практику концепции экосистемных услуг в условиях глобального рынка, когда повсеместно происходит количественная оценка окружающих объектов, необходимо для обеспечения эффективности управленческих решений, рационального распределения бюджетных средств, повышения эффективности природоохранной деятельности и качества жизни населения в регионах [8].

Все чаще встречаются случаи противостояния местных жителей и экологов с коммерческими предприятиями, организациями, нацеленными на получение прибыли от хозяйственного использования территорий ценных природных комплексов. Проводимые при этом оценки воздействия на окружающую среду проводятся с нарушениями, фрагментарно и субъективно, в интересах получателей материального вознаграждения. Примерами таких случаев могут служить следующие:

- События 2007-2012 гг., связанные с решением Министерства транспорта РФ по строительству трассы через Химкинский лес, обладающий высокой фильтрационной способностью воздуха, являющийся местообитанием редких и находящихся под угрозой исчезновения видов животных и растений, а также выполняющий рекреационную функцию для жителей Москвы и Московской области.

- Реализация проекта по реконструкции участков автомобильной дороги А-180 «Нарва» от СанктПетербурга до границы с Эстонской Республикой (на Таллин), подвергшая разрушению мест зимовок редких видов летучих мышей в пещерах Телези Ломоносовского муниципального района Ленинградской области в 2013 г. [9];

- Строительство Западного скоростного диаметра вблизи Юнтоловского заказника г. СанктПетербурга в 2011 г., в ходе которого обнаружена и изъята из естественной среды популяция восковника болотного Myrica gale, занесенного в Красную книгу РФ [9];

- Строительство газопровода «Северный поток 2», начатое в 2018 г., через Кургальский заказник, имеющий международный статус ООПт: водноболотное угодье международного значения; охраняемый район Балтийского моря (ХЕЛКОМ); включен в международную сеть ООПТ [10];

- Работы по строительству глубоководного универсального портового комплекса «Приморский универсально-перегрузочный комплекс», начатые в 2019 г. без согласования проекта и получения по- 
ложительного заключения экологической экспертизы, на побережье Финского залива с включением в зону проектирования Высокинского озером - уникального природного комплекса, служащим местообитанием редким видам, в т.ч. занесенным в Красную книгу РФ.

Все перечисленные случаи подтверждают необходимость экономической обоснованности ценности природных комплексов, доказывающей превалирование выгоды в долгосрочной перспективе от сохранения экосистем перед антропогенным преобразованием.

В связи с этим целесообразно внедрение универсальной экономической оценки экосистемных услуг и биоразнообразия с размещением полученных расчетов стоимости в картографических сервисах и прочих базах данных, находящихся в доступе уполномоченных на принятие в сфере природопользования решений лиц.

В рамках унифицированной методики экономической оценки экосистем предлагается сочетание использования удельных величин стоимости экосистемных услуг (руб. на га в год) вместе с отдельно рассчитанной стоимостью эксплуатируемых объектов животного и растительного мира и представителей видов, занесенных в красные книги и списки, для каждого типа биома.

Перечисленные показатели, приведенные к удельным величинам, могут стать основой экспресс-метода экономической оценки любой экосистемы, для которой необходимо будет определить набор первоначальных параметров: тип биома, площадь, видовой состав.

Остальные показатели могут быть определены на основе рассчитанных удельных показателей стоимости подходящих экосистемных услуг биома и обитающих видов на данной территории.

Кроме того, при определении ведущих экологических услуг, поставляемых конкретной экосистемой, и их стоимости появляется возможность организации более эффективного освоения данной территории, а также расчета адекватной платы за пользование природными ресурсами.

Таким образом, применение экономического механизма при организации природоохранной деятельности и осуществлении природопользования в условиях глобализации рыночных отношений является необходимым условием обеспечения устойчивого развития. Проведение универсальной экономической оценки экосистемных услуг позволит избежать ошибок при планировании мероприятий по освоению территорий в соответствии с их рекреационным и экономическим потенциалом, а также предотвратить сокращение биологического разнообразия и риск уничтожения редких и находящихся под угрозой исчезновения видов, способствуя более эффективному распределению бюджетных средств на охранные мероприятия и принятию управленческих решений экологически обоснованных экономическим механизмом.

\section{ЛИТЕРАТУРА}

1. Оценка экосистем на пороге тысячелетия (0Э). Экосистемы и благосостояние человека: деловые круги и промышленность - возможности и проблемы // Научный отчет Международной Программы 0Э. - Island Press, Washington DC, 2005. С. 123-130.

2. Пятый национальный доклад «Сохранение биоразнообразия в Российской Федерации». М.: Министерство природных ресурсов и экологии Российской Федерации, 2015. 124 с.

3. Costanza R. et al. The value of the world's ecosystem services and natural capital // Nature. 1997. V. 387. P. 253-260.

4. История науки. Самарская Лука: проблемы региональной и глобальной экологии. 2011. Т. 20, N 1. С. 185-204.

5. 06 охране окружающей среды: Федеральный закон РФ от 10.01.2002г., с изм. от 03.07.2016 N 358-Ф3 №7-Ф3 // Собрание законодательства Российской Федерации, 2002. N 2.

6. Об утверждении такс для исчисления размера вреда, причиненного объектам растительного мира, занесенным в Красную книгу Российской Федерации, и среде их обитания вследствие нарушения законодательства в области охраны окружающей среды и природопользования: Приказ Министерства природных ресурсов и экологии Российской Федерации от 1 августа 2011 года N 658 // Российская газета, 2011, N 216.

7. $0 б$ утверждении Методики исчисления размера вреда, причиненного объектам животного мира, занесенным в Красную книгу Российской Федерации, а также иным объектам животного мира, не относящимся к объектам охоты и рыболовства и среде их обитания: Приказ Министерства природных ресурсов и экологии Российской Федерации от 28 апреля 2008 года // Бюллетень нормативных актов федеральных органов исполнительной власти, 2008. N 26.

8. Вахрушева К. Экономическая оценка экосистемных услуг //Экология и право. СПб: Беллона, 2016. N 2 (62). С. 4-5.

9. иириллова Ю.А. Анализ эффективности Красных книг и красных списков на примере территории г. Санкт-Петербурга и Ленинградской области // СПбГУ, 2017. URL: https://dspace.spbu.ru/bitstream/11701/7528/1/Diplomnaya_rabota_Kirillova_YU_A_pdf (дата обращения: 25.08.2020).

10. Кургальский // 00ПT России URL: http://oopt.aari.ru/оopt/Кургальский (дата обращения: 25.08.2020).

(с) Кириллова Юлия Александровна (yulya_kirillova6@mail.ru). 